\title{
Dos Seguros Supostamente Garantidos por Seguradores Estrangeiros sem Operação Regular no Brasil. Fraude a Consumidores e a Segurados em Geral
}

\author{
Pedro Baumgarten Cirne Lima ${ }^{1}$
}

SUMÁRIO

I - INTRODUÇÃO

II - DA ORIGEM DO CONTRATO DE SEGURO E DAS COMPANHIAS SEGURADORAS

III - QUEM PODE ATUAR COMO SEGURADOR NO MERCADO BRASILEIRO IV - DAS EXIGÊNCIAS IMPOSTAS AO SEGURADOR PELO SISTEMA NACIONAL DE SEGUROS

PRIVADOS

V-DA IMPORTÂNCIA DA FISCALIZAÇÃO E DO CONTROLE DO SISTEMA NACIONAL DE

SEGUROS PRIVADOS PELASUSEP

VI- DANECESSÁRIA INTERVENÇÃO DO IRB NO REPASSE DE SEGUROS OU RESSEGUROS AO

EXTERIOR

VII - DANULIDADE DO CONTRATO E DAOBRIGAÇÃO DE INDENIZAR PELO ATO ILÍCITO.

VIII - DA POSSIBILIDADE DE ENQUADRAMENTO DAS CONDUTAS DO SUPOSTOAGENTEOU

REPRESENTANTE DO SEGURADOR E DO CORRETOR DE SEGUROS NAS HIPÓTESES PREVISTAS

NO CÓDIGO DE DEFESA DO CONSUMIDOR

IX-CONCLUSÃO

BIBLIOGRAFIA

${ }^{1}$ Advogado, Especialista em Direito da Empresa e da Economia pela Escola de Pós-Graduação em Economia da Fundação Getúlio Vargas 


\section{I - INTRODUÇÃO}

O objetivo desse pequeno estudo é alertar aos contratantes de seguros privados em geral, sejam pessoas físicas ou jurídicas, sobre as conseqüências de fraudes que vêm sendo perpetradas no mercado nacional de seguros privados, em especial nos chamados ramos elementares, com a comercialização de seguros supostamente contratados com seguradoras sediadas em outros países, não constituídas como Sociedades Seguradoras no Brasil e, por conseguinte, sem autorização para aqui exercer suas atividades.

Tais "seguros", geralmente oferecidos por pseudorepresentantes com a suposta chancela de grandes seguradores internacionais, por serem bastante mais baratos que os similares nacionais (o que, mais tarde, se verificará decorrer da inexistência de custos, já que seguro não existe, pois o segurador referido no contrato, além de não estar autorizado a atuar no Brasil, não o assina, tendo seu nome indevidamente utilizado) despertam a atenção de pessoas físicas e jurídicas que, premidas pela necessidade cada vez maior de controle de custos, enxergam neles uma boa alternativa para manter seu patrimônio, ou o de terceiros que eventualmente lhes é confiado, garantido contra sinistros, a um custo mais baixo do que o habitualmente ofertado.

As respostas dadas pelos ofertantes desses seguros, quando confrontados com a inevitável pergunta, "Mas o seguro é válido, mesmo não tendo a seguradora autorização para atuar no mercado brasileiro?", são as mais criativas. Vão desde confusas explicações envolvendo regras das operações de resseguro, pouco conhecidas pelos leigos, passando pela suposta desnecessidade de autorização a partir do processo de desregulamentação do setor iniciado em 1992, chegando inclusive à apresentação de interessantes teses jurídicas, teses essas que, todavia, não vêm acompanhadas da necessária chancela do Poder Judiciário a amparar uma contratação proibida por lei (como se verá a seguir, para ser autorizada a operar como seguradora no Brasil, a empresa 
necessita de autorização concedida através de Portaria do Ministro da Indústria e do Comércio).

Todavia, esses contratos acabam por se revelar lamentáveis fraudes, geralmente bem elaboradas, com a apresentação de um contrato padrão, similar aos contratos de seguros brasileiros, acompanhados das condições gerais, sem que, entretanto, o suposto "garantidor" do seguro (normalmente alguma conhecida seguradora européia ou norte-americana sem atuação no Brasil), tenha qualquer participação ou mesmo conhecimento do contrato nem, conseqüentemente, qualquer responsabilidade sobre a "apólice" vendida ao lesado contratante.

Para evitar a ocorrência de tais fraudes, a mera observância da lei já seria suficiente, pois, ao se deparar com uma "tentadora" oferta similar à acima descrita, basta ao interessado, seja ele pessoa física ou jurídica, atentar para o que determinam os diplomas legais que disciplinam o funcionamento dos seguros privados no Brasil. O exame da proposta de seguros à luz dos ditames legais, principalmente no que diz respeito à capacidade da companhia seguradora que a subscreve para operar como tal, pode evitar os pesados dissabores advindos da contratação de um seguro "fantasma".

Entretanto, em muitas oportunidades, tal cuidado é posto de lado, levando à efetiva contratação, que, por ocasião da efetivação de eventual sinistro, acaba por deixar o segurado sem a cobertura contratada.

Nas linhas a seguir traçadas, busca-se ressaltar, através de uma análise do ponto de vista jurídico, a importância do criterioso exame, pelo interessado, da proposta de seguro que the é apresentada, bem como sugerir alternativas possíveis na defesa de seus interesses, na hipótese de efetiva assinatura de tal espécie de contrato e da verificação de sinistro. 


\section{II - DA ORIGEM DO CONTRATO DE SEGURO E DAS COMPANHIAS SEGURADORAS}

Segundo a melhor doutrina, na Antiguidade não se conheceu o contrato de seguro, o qual teria surgido no final da ldade Média, a partir da necessidade de maior segurança para aqueles negociantes que faziam investimentos de vulto no crescente transporte marítimo de mercadorias.

Admite Pedro Alvim que existiam, na idade antiga, institutos próximos ao do seguro, como as sociedades de socorro mútuo surgidas na Ásia e desenvolvidas pelos gregos, sob o nome de sinedrias, hetarios ou heranos, e igualmente em Roma, onde eram conhecidas como sodalitia ou collegia. ${ }^{2}$

Compartilham dessa opinião, entre outros, Silvio de Salvo Venosa ${ }^{3}$ e Pontes de Miranda que, em seu "Tratado de Direito Privado", afirma que o direito romano ignorou o contrato de seguro, que teve origem no transporte por mar e, embora refira que, na Idade Média, havia institutos parecidos, mas não idênticos ao

2. "A forma primitiva em que se pode filiar a idéia rudimentar de seguro - escreve Fernando Emygidio da Silva - confunde-se com o socorro mútuo, no seu sentido mais amplo e duma organização de pessoas que se prestem reciprocamente serviços por meio de um fundo comum de qualquer maneira constituído.A história registra a exisțência dessas sociedades desde remota antigüidade. Segundo Plínio, funcionavam na Ásia ad sustinendam tenuiorum inopiam. Esclarece o citado autor Fernando Emygidio da Silva que os gregos deram um largo desenvolvimento ao princípio associativo em todas as suas formas, religiosa, política, comercial, marítima - e como tal criaram, sob o nome de sinedrias, hetarios ou heranos, sociedades do tipo do socorro mútuo. (...) Aparecem também em Roma, sob a denominação de sodalitia ou collegia." (O Contrato de Seguro, $3^{a}$ ed. Rio de Janeiro: Forense, 1999, pag. 3) 3. "O seguro surge inicialmente no direito marítimo da Idade Média. Embora possuísse institutos próximos, a Antiguidade não conheceu este contrato." (Direito Civil, $4^{a}$ ed. São Paulo: Atlas, 2004, vol. 3, pág. 384) 
seguro, em momento posterior, faz referência à existência de apólices de seguro naquele período histórico ${ }^{4}$

As primeiras apólices de seguro conhecidas, segundo Alvim, são uma de Pisa, datada de 11 de julho de 1385, e outra de Florença, datada de 10 de julho de 1397. A partir de então, o seguro teria obtido impulso considerável, com a crescente assinatura de contratos, surgindo no século XV, nas Ordenanças de Barcelona, em 1435, as primeiras disposições legais relativas a tal espécie de contrato, com a criação de um tribunal especializado para julgamento da matéria. ${ }^{5}$

Inicialmente, os seguradores eram comerciantes que se reuniam em grupos, garantindo as operações de transporte marítimo das quais participavam contra os infortúnios tão comuns naquela época e que poderiam, na ausência de tal espécie de garantia, levá-los à insolvência.

Pontes de Miranda faz referência ao início da sucessão desses grupos de seguradores, os seguradores em comum, pelas empresas seguradoras já no século XVII. ${ }^{6}$

Alvim afirma que, com o avanço das transações comerciais, a figura do segurador individual, pelas mais diversas razões (dentre as quais a falta de condições de uma pessoa individualmente estruturar técnica e economicamente um

4. "4. FONTES DO DIREITO DE SEGURO - o direito romano ignorou o contrato de seguro. É insustentável a opinião contrária de P. Huelvin (Etudes d'Historie du Droit Commercial romain, $95 \mathrm{~s}$ ). Na Idade Média, há institutos parecidos, porém não idênticos, quais os pactos de comunhão de danos sofridos pelos cidadãos, se se desconheciam os causadores, e os vínculos entre membros da mesma ou diferentes corporações mercantis (cf. F. Schupfer, Ill Diritto dell' Obbligazioni in Itália nell' Età del Risorgimento, 211-261). Se semelhanças com o mútuo a risco levou a pensarse em que nesse estivesse a origem do contrato de seguro, por ser a prestação do mutuário "seguro antecipado" (LEVIN GOLDSCHMIDT); mas é forçada a afirmação de continuidade histórica. O transporte por mar criou o contrato de seguro.(...) A apólice de seguro, já na Idade Média teve parata executio e prompta executio" (Tratado de Direito Privado: direito das obrigações, $2^{a}$ ed. Rio de Janeiro: Borsol, 1964, tomo XLV, págs. 277/278).

5. Ob. cit., pág. 28.

6 "As companhias de seguro sucederam aos seguradores em comum, coseguradores, mas já no século XVII." (GIOVANI CASSANDRO, Assicurazione [storia], Enciclopedia del Diritto, III, 426). Ob. cit, Tomo XVL, pág. 278. 
empreendimento de seguros), foi perdendo aceitação, passando a doutrina a admitir de forma unânime, principalmente em razão do esforço de Vivante neste sentido, que o seguro deve ser

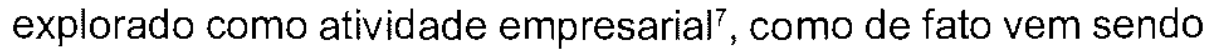
explorado atualmente, estando a possibilidade de operação de seguradores individuais hoje limitada à Inglaterra, onde se reúnem sob o pálio do Lloyd's of London, organização tradicional e que ainda goza de prestígio em todo o mundo.

\section{III - QUEM PODE ATUAR COMO SEGURADOR NO MERCADO BRASILEIRO}

Durante muito tempo, as leis que regulavam a contratação de seguros não se preocuparam em criar restrições à capacidade dos contratantes, podendo qualquer pessoa, física ou jurídica, desde que dotada dos recursos necessários e contando com segurados interessados, atuar como segurador.

Embora, segundo Pedro Alvim, não se tenha notícia da operação no Brasil, em caráter esporádico e regular, de seguradores individuais, tendo o seguro surgido em nosso país já através da figura da sociedade seguradora ${ }^{8}$, a priori, qualquer pessoa, física ou jurídica, com capacidade para assumir obrigações poderia firmar um contrato de seguro na posição de segurador.

Aliás, a leitura do Código Civil Brasileiro vigente até 10 de janeiro de 2003 , Lei $n^{\circ} 3.071$, de $1^{\circ}$ de janeiro de 1916 , por certo

7. "Coube a Vivante o mérito de iniciar a luta contra os seguradores individuais, mostrando que se trata de uma atividade que não comporta as operações isoladas ou eventuais. Só a empresa de seguros com suporte econômico e técnico e um trabalho permanente pode consolidar suas operações e oferecer garantia a seus segurados" (ob. cit., pág. 179)

8."Não há notícia de ter operado em nosso país algum segurador individual, explorando essa atividade em caráter esporádico ou regular... (...) A primeira seguradora, criada em princípios de 1808, na Bahia, já surgiu sob a forma empresarial, como sociedade de capital. Outras se constituíram pelo mesmo processo, sob a tutela da legislação comum sobre sociedades anônimas." (ob. cit., págs. 183/184). 
induziria a esse raciocínio, uma vez que seu artigo 1.432, inserido na seção I do Capítulo XV, que trata das disposições gerais do Contrato de Seguro, definia como sendo o contrato de seguro "aquele pelo qual uma das partes se obriga para com a outra, mediante a paga de um prêmio, a indenizá-la do prejuizo resultante de riscos futuros, previstos no contrato." ${ }^{9}$

Todavia, não é esta a realidade pois, por força do Sistema Nacional de Seguros Privados (seguros privados englobam os seguros de coisas, pessoas, bens, responsabilidades, obrigações, direitos e garantias), criado através do Decreto-Lei $n^{\circ} 73$, de 21 de novembro de 1966 e regulamentado pelo Decreto $n^{\circ} 60.459$, de 13 de março de 1967, estão estabelecidos quais tipos de pessoas jurídicas podem realizar operações de seguro no Brasil e mediante que condições.

No artigo 24 do $D L 73 / 66$, está estabelecido que somente as Sociedades Anônimas ou Cooperativas, devidamente autorizadas, podem operar em seguros privados, sendo que, às últimas, é possível apenas atuar em seguros agrícolas, de saúde e acidentes do trabalho. ${ }^{10}$

A respeito da atuação das cooperativas, importante considerar a observação de Waldírio Bulgarelli, de que estão impedidas de atuar por falta de regulamentação do DL 73/66 na parte relativa a elas ${ }^{11}$, o que explica a correção da afirmação de que apenas as sociedades anônimas podem atuar como seguradoras no mercado brasileiro.

9. "Art. 1.432. Considera-se contrato de seguro aquele pelo qual uma das partes se obriga para com a outra, mediante a paga de um prêmio, a indenizá-la do prejuízo resultante de riscos futuros, previstos no contrato.

"t0. "Art. 24. Poderão operar em seguros privados somente Sociedades Anônimas ou Cooperativas, devidamente autorizadas. Parágrafo único. As Sociedades Cooperativas operarão unicamente em seguros agrícolas, de saúde e de acidentes do trabalho."

11."No Brasil, adotou-se, com o Decreto-lei no 73, de 21 de novembro de 1996, um sistema de seguros (...), permitindo-se que atuem, como seguradores, apenas sociedades anônimas (e com tipo específico, capital, ações etc. regulamentados) e cooperativas (estas, porém, até hoje impedidas de atuar no campo dos seguros, por terem os responsáveis oficiais esquecido de regulamentar o Decreto no 73, na parte referente a elas)." (Contratos Mercantis, $10^{\mathrm{a}}$ ed. São Paulo: Atlas, 1998, pág. 638) 
Portanto, nos termos Decreto-Lei $n^{\circ} 73 / 66$, que cria o Sistema Nacional de Seguros Privados e estabelece suas diretrizes, e do Decreto $n^{\circ} 60.459 / 67$, que o regulamenta, com a ressalva feita às Cooperativas, na prática, somente as Sociedades Anônimas devidamente autorizadas pela autoridade estatal podem atuar como seguradores. E essa autorização, segundo determina o art. 74 do DL 73/66, é concedida pelo Ministro da Indústria e Comércio, através de Portaria, a partir de requerimento dos incorporadores, dirigido ao CNSP (Conselho Nacional de Seguros Privados) e apresentado pela SUSEP (Superintendência Nacional de Seguros Privados). ${ }^{12}$

No mesmo sentido, o atual Código Civil Brasileiro, Lei $\mathrm{n}^{0}$ $10.406 / 02$, deixa claro que existem restrições à capacidade do segurador, pois, embora o caput do art. 757 , praticamente repita os termos do artigo 1.432 da lei civil anterior, ao definir o contrato de seguro como aquele pelo qual "o segurador se obriga, mediante pagamento do prêmio, a garantir interesse legítimo do segurado, relativo a pessoa ou coisa, contra riscos predeterminados", referido artigo prevê, no seu parágrafo único, que somente poderá contratar como segurador "entidade para tal fim legalmente autorizada." ${ }^{13}$

\section{IV - DAS EXIGÊNCIAS IMPOSTAS AO SEGURADOR PELO SISTEMANACIONAL DE SEGUROS PRIVADOS}

Em relação aos seguradores, o anteriormente mencionado Sistema Nacional de Seguros Privados estabelece uma série de exigências, as quais se mostram totalmente pertinentes para assegurar o cumprimento das obrigações contratadas com os

12. "Art. 74. A autorização para funcionamento será concedida através de Portaria do Ministro da Indústria e do Comércio, mediante requerimento firmado pelos incorporadores, dirigido ao CNSP e apresentado por intermédio da SUSEP".

13 "Art. 757. Pelo contrato de seguro, o segurador se obriga, mediante o pagamento do prêmio, a garantir interesse legítimo do segurado, relativo a pessoa ou coisa, contra riscos predeterminados. Parágrafo único. Somente pode ser parte, no contrato de seguro, como segurador, entidade para tal fim legalmente autorizada. 
segurados na hipótese de verificação de sinistros, garantindo a estabilidade e confiabilidade do sistema.

Em primeiro lugar, cabe-nos elencar, de forma genérica, quais as principais exigências que a legislação brasileira estabelece para reconhecer a capacidade de uma empresa para atuar como companhia seguradora no país e autorizar-Ihe o funcionamento como tal.

Esses requisitos legais estão fixados no Decreto-Lei $n^{\circ}$ $73 / 66$, regulamentado pelo Decreto $n^{\circ} 60.459 / 67$, que "dispõe sobre o Sistema Nacional de Seguros Privados, regula as operações de seguros e resseguros e dá outras providências".

Em seu Capitulo VII, o DL 73/66 trata "Das Sociedades Seguradoras", estabelecendo, no artigo 72 , que serão reguladas pela legislação geral, no que for aplicável, e especialmente pelas disposições do Decreto-Lei.

No artigo seguinte (73), o texto legal estabelece que as seguradoras não poderão explorar qualquer outro ramo de comércio ou indústria, limitando suas atividades às de operação em seguros privados.

A Seção II (artigos 74 a 76) do Capítulo VII do DL 73/66 e a Seção I (artigos 42 a 47) do Capítulo VI do Dec. 60.459/67 tratam da autorização para funcionamento das companhias seguradoras, que será concedida através de através de Portaria do Ministro da Indústria e Comércio.

Inicialmente, os incorporadores devem apresentar, via SUSEP (Superintendência de Seguros Privados), requerimento ao CNSP (Conselho Nacional de Seguros Privados), instruído com prova da regularidade da constituição da Sociedade, depósito perante o Banco do Brasil da parte do capital já realizada e cópia do estatuto social.

O pedido de autorização é submetido, pela SUSEP, à apreciação pelo CNSP que, após analisá-lo frente aos critérios estabelecidos nas alineas "a" a "f" do art. 43 do Dec. 60.459/67 (dentre os quais podemos destacar a saturação e a possibilidade do mercado segurador nacional, a probabilidade de êxito de suas 
operações e a regularidade de constituição da sociedade), opinará sobre a concessão ou não do requerimento.

Publicada a Portaria de autorização de funcionamento e comprovados, perante a SUSEP, a subscrição de ações do Capital do IRB (Instituto de Resseguros do Brasil), a efetivação de todos os registros e publicação de atos exigidos por lei para seu funcionamento, a satisfação das exigências eventualmente constantes da Portaria de Autorização e o cumprimento das exigências suplementares estabelecidas pela SUSEP (art. 45 do Dec. 60.459/67), será expedida pelo Ministro da Indústria e do Comércio, tal como ocorre com as instituições financeiras, uma Carta Patente para funcionamento da Sociedade. Este documento, uma vez registrado na SUSEP, arquivado no órgão do Registro do Comércio da sede da Sociedade e tendo publicada sua certidão de arquivamento no "Diário Oficial" da União, desde que preenchidas as demais exigências legais, dará direito ao início das operações da seguradora (art. 46 do Dec. 60.459/67).

Importante ainda ressaltar que, nos termos do art. 78 do DL 73/66, a Seguradora somente poderá operar nos seguros para os quais especificamente possua autorização, de acordo com os planos, tarifas e normas aprovadas pelo CNSP.

Nos termos do artigo 48 do Dec. 60.459/67, o CNSP estabelece um capital inicial mínimo para operação nos seguros de direitos, coisas, obrigações e bens, além de capitais adicionais para atuação em seguros de responsabilidades, de garantia, de acidentes pessoais, de saúde e de pessoas. Referidos capitais devem sofrer atualização pelo CNSP com periodicidade mínima de dois anos, nos termos do $\$ 2^{\circ}$ do mencionado art. 48 .

Em razão de não haver sido regulamentada a Lei $n^{\circ} 5.627 /$ 70 , que determina a variação dos capitais mínimos para cada ramo, de acordo com as regiões geográficas do país, vige a decisão do CNSP, segundo a qual os capitais mínimos são fixados para seguros de dois grandes grupos, os de ramos elementares e os de vida. Atualmente (junho de 2004), o capital mínimo exigido de uma seguradora de atuação nacional, para operação nos seguros 
de ramos elementares, segundo informação da SUSEP, não poderá ser inferior a $\mathrm{R} \$ 7.200 .000,00$ (sete milhões e duzentos mil reais).

Exige ainda o DL 73/66, em seu art. 84, como medida para garantir 0 atendimento, pelas Sociedades Seguradoras, das obrigações por elas assumidas, a constituição de reservas técnicas, fundos especiais e provisões, dentro de critérios estabelecidos pelo CNSP, assim como reservas e fundos determinados em leis especiais.

A destacar ainda o artigo 63 do Decreto regulamentador do sistema, que impõe às Sociedades Seguradoras o dever de dar publicidade a seus atos, obrigando-as a publicar anualmente seus balanços, contas de lucros e perdas e pareceres dos respectivos Conselhos Fiscais, a realizar anualmente sua Assembléia Geral Ordinária e a enviar a ata à SUSEP, juntamente com as atas das demais Assembléias Gerais eventualmente realizadas, bem como a manter, na matriz e nas sucursais, a escrituração completa das operações efetuadas.

Tais exigências demonstram a preocupação do legislador brasileiro em dotar o sistema nacional de seguros privados de mecanismos capazes de controlar a regularidade de constituição das Sociedades Seguradoras e de seu funcionamento e a capacidade dessas empresas de honrar os riscos segurados, bem como em possibilitar a identificação e responsabilização dos administradores por irregularidades ou ilegalidades eventualmente promovidas.

\section{V - DA IMPORTÂNCIA DA FISCALIZAÇÃO E DO CONTROLE DO SISTEMA NACIONAL DE SEGUROS PRIVADOS PELA SUSEP}

Diante das colocações acima expendidas, resta patente a importância, para o mercado segurador brasileiro, do Sistema Nacional de Seguros Privados, cuja composição e funcionamento estão disciplinados basicamente pelo Decreto-Lei $n^{\circ} 73 / 66$, regulamentado pelo Decreto $n^{\circ} 60.459 / 67$, não se tratando sua 
existência de mero apego ao formalismo legal ou de burocracia estatal criada para gerar empregos ou dificultar a efetivação dos contratos de seguro.

Apenas para demonstrar a importância da fiscalização estatal sobre a atividade securitária, no início do século XX, Clóvis Beviláqua já fazia menção a respeito, tratando o tema como "face importante do sistema de seguros." "14

Feito esse pequeno parêntese histórico, retornemos ao Sistema Nacional, que é composto por três órgãos oficiais, o Conselho Nacional de Seguros Privados (CNSP), a Superintendência de Seguros Privados (SUSEP) e o Instituto de Resseguros do Brasil (IRB), cada um com sua função específica, além das Sociedades Seguradoras autorizadas e dos corretores habilitados, e disciplina as operações de seguros privados no país. Através dos supra mencionados textos legais, define direitos e obrigações de cada um dos seus participantes, estabelece formas de controle e penalidades para quem descumprir as determinações legais, o que possibilita o regular funcionamento do mercado e, em última análise, busca evitar a ocorrência de prejuizos aos segurados, esses entendidos como as pessoas físicas ou jurídicas que buscam garantir seu patrimônio, ou o patrimônio de terceiros, contra os mais diversos riscos, tais como furtos, roubos, acidentes, extravios, intempéries, etc.

O papel da SUSEP, nos termos do disposto nos artigos 36 do DL 73/66 e 33 do Dec. 60.459/67, é o de executora da política de seguros estabelecida pelo CNSP (que, por sua vez, é o órgão

"14. "II. Uma face importante do problema dos seguros, relativamente cedo, despertou a attenção do nosso legislador: a fiscalização das sociedades de seguro por parte do governo, e a sua organização obedecendo às normas garantidoras dos interesses particulares confiados às mesmas. $(1)^{\prime \prime} \ldots$

(1) Vejam-se Relatorios do inspector de seguros, Dr. Verne Abreu, em 1906 e 1908. (Direito das Obrigações, Campinas: Red Livros, 2000, pág. 496) El Estado asume, por lo tanto, una obligación jurídica de garantía que consiste en asegurar el correcto funcionamiento del servicio del sistema asegurativo, a fin de no frustrar la efectiva reparación de los damnificados ante una eventual insolvencia de la empresa aseguradora." (Contratos civiles y comerciales, $4^{a}$ ed. Buenos Aires: Astrea, 1999, págs. 479/480) 
consultivo, organizador do Sistema Nacional de Seguros) cabendoIhe a fiscalização da constituição, organização, funcionamento e operações das Sociedades Seguradoras.

Sendo assim, cabe à SUSEP, a quem a lei não apenas dá poder, mas estabelece o dever de fiscalizar as operações de seguro no país, coibir quaisquer irregularidades ou ilegalidades verificadas no mercado segurador, inclusive eventuais operações de seguros ilegais, contratadas por falsos representantes de empresas que não têm autorização para funcionar, no Brasil, como Seguradoras.

Em outros paises, onde semelhante sistema de controle estatal existe, a importância da atuação do ente executor da política estatal de seguros na fiscalização do mercado de seguros privados é igualmente reconhecida. O prof. Carlos Alberto Ghersi na obra intitulada "Contratos civiles y comerciales" ressalta a responsabilidade da Superintendencia de Seguros de lá Nacion, órgão estatal argentino similar à SUSEP brasileira, nos termos da lei daquele país, afirmando que o Estado assume a obrigação jurídica de garantia, consistente em assegurar o correto funcionamento do sistema de seguros, para garantir aos segurados a efetiva reparação dos danos sofridos mesmo em caso de eventual insolvência do agente segurador. ${ }^{15}$

\section{$(\ldots)$}

Como se vê, o papel do Estado enquanto ente fiscalizador dos mercados, particularmente do mercado de seguros privados, é tema relevante, merecedor de abordagens pelos doutrinadores nacionais e estrangeiros, exatamente pelo fato de que é obrigação

\footnotetext{
15."La ley 20.091 determina con claridad el sometimiento de la actividad aseguradora a su régimen y el control de la autoridad de la Superintendencia de Seguros en forma exclusiva y excluyente; su intervención no se limita a la autorización para operar en seguros, sino que se prolonga durante toda la vida da la aseguradora mediante una efectiva fiscalización, para lo cual ésta debe adoptar todas las medidas adecuadas con el objeto de mantener la indemnidad de su patrimonio.
} 
do governo assegurar o correto funcionamento do Sistema Nacional de Seguros Privados.

Mas o reconhecidamente necessário controle oficial do mercado de seguros privados, em especial no que se refere às operações contratadas por falsos representantes de empresas que não são Sociedades Seguradoras autorizadas a atuar no Brasil, somente pode ser adequadamente exercido em sua plenitude se houver respeito, pelos seguradores, corretores, estipulantes e demais agentes do mercado segurador, inclusive segurados, às regras estabelecidas para as operações de seguros privados, evitando a oferta e a contratação de seguros que não sejam firmados e garantidos por seguradoras autorizadas. Em especial no que se refere à comercialização, cada vez mais corrente, dessa espécie de contratos, supostamente garantidos por seguradoras estrangeiras, pessoas jurídicas sem qualquer espécie de registro junto à SUSEP e, conseqüentemente, sem autorização para atuar no mercado segurador brasileiro (muitas vezes, inclusive sem constituição regular no Brasil), pouco pode fazer a Superintendência quanto à preservação do patrimônio do segurado.

Estes contratos, não reconhecidos como operações de seguros pela lei brasileira, na maior parte das vezes (se não em todas), sequer têm a efetiva participação das seguradoras estrangeiras neles mencionadas como garantidoras do risco, sendo seus nomes indevidamente utilizados para perpetrar fraudes contra o consumidor brasileiro, fraudes essas cujos mentores não apresentam, via de regra, patrimônio suficiente para garantir o cumprimento das obrigações contratadas em casos de sinistro.

E é aí que surge a dificuldade de atuação da SUSEP, na medida em que, embora exista punição prevista pelo CNSP para as hipóteses de pessoa física ou jurídica que realizar operações de seguro sem autorização, consistente em multa no valor igual ao da importância segurada (artigos $8^{\circ}$ e $9^{\circ}$ da Resolução CNSP no 60/01), a pena, na prática, se revela inócua quando aplicada contra pessoas físicas ou jurídicas sem patrimônio algum, como é o caso da maioria daquelas que se aventuram a contratar seguros sem autorização para tanto. 
Neste ponto se revela a importância do respeito ao sistema e ao controle estatal, via SUSEP, das operações e das seguradoras, na medida em que, se estivéssemos a tratar de ilegalidade cometida por seguradora regularmente constituída sob a forma de sociedade anônima e autorizada a atuar no Brasil, essa certamente teria reservas de capital suficientes para responder por seus atos, e seus dirigentes e acionistas, por certo, não teriam interesse em receber punições pecuniárias, temendo o abalo da marca da empresa junto ao mercado de seguros.

Já o mesmo não se pode dizer dos falsos seguradores, que por vezes sequer pessoa jurídica regularmente constituida representam, pouco lhes importando a aplicação de multa pecuniária, pois não possuem bens capazes de pagá-la, tampouco o abalo da marca no rnercado, pois geralmente se utilizam, de forma indevida, de marca alheia.

Daí que, no aspecto atinente à preservação dos interesses daquele segurado que, de boa-fé, contrata seguro fraudulento, pouco podem fazer os integrantes do Sistema Nacional de Seguros Privados, cabendo ao próprio lesado buscar ressarcimento junto ao pretenso agente do segurador.

\section{VI - DA NECESSÁRIA INTERVENÇÃO DO IRB NO} REPASSE DE SEGUROS OU RESSEGUROS AO EXTERIOR

Segundo os termos do "caput" do art. 81 do Decreto-Lei no $60.459 / 67$, qualquer operação de resseguro ou seguro no exterior é necessariamente efetuada através do IRB. ${ }^{16}$

Embora o monopólio do IRB tenha sido relativizado com o início do processo de privatização do instituto, através da revogação do dispositivo legal acima transcrito pela Lei n 9932/99, a eficácia dessa lei está suspensa por meio de medida liminar, concedida pelo Supremo Tribunal Federal nos autos das Ações Diretas de

\footnotetext{
16. "Art. 81. A colocação de seguro e resseguro no estrangeiro será feita exclusivamente por intermédio do IRB.
} 
Inconstitucionalidade $n^{\circ} s 2244$ e 2223 , que ainda pendem de julgamento definitivo ${ }^{17}$.

Surge, assim, mais um motivo para o questionamento, pelo segurado, quanto à validade do seguro, pois, se o risco, em parte ou integralmente, é repassado a empresa estrangeira, necessária se faria a intermediação do IRB, que não se faz presente nessas obscuras contratações.

\section{VII - DA NULIDADE DO CONTRATO E DA OBRIGAÇÃO DE INDENIZAR PELOATO ILÍCITO.}

Frustrado o segurado na tentativa de receber o valor da indenização correspondente à cobertura pactuada, ao descobrir que o segurador não possui autorização para atuar como segurador no Brasil e que sequer firmou o contrato, mas sim seu alegado agente ${ }^{18}$, que, em verdade, não o representa, deve se voltar contra este último na defesa de seus interesses.

De início, salta aos olhos o inegável dolo contido no agir do firmatário do contrato, que se utiliza de artifício para induzir o segurado a praticar ato que vem em seu prejuizo e em favor do primeiro. Ao distinguir o dolo da lesão, Marcelo Guerra Martins, de maneira sintética e precisa, o define como "um erro provocado pela artimanha e má-fé de um dos contratantes". ${ }^{19}$

\footnotetext{
"17. A ADI 2223, proposta pelo PT (Partido dos Trabalhadores) teve a liminar concedida referendada pelo Pleno do TST em 10.12.02, decisão publicada no D.J e no D.O.U. em 05.12.03, estando atualmente com vista ao Advogado Geral da União e ADI 2244, proposta pelo PC do B (Partido Comunista do Brasil), fol retirada de pauta em 19.12.03, decisão publicada no D.J e no D.O.U. em 13.02.04. ${ }^{18}$. A referência a agente do segurador é extraída do art. 775 do CCB que, ao que parece, prevê o estabelecimento de contratos de agência, nos termos daqueles previstos nos artigos 710 a 721 do CCB, entre seguradoras e agentes autorizados a representá-las: "Art. 775. Os agentes autorizados do segurador presumem-se seus representantes para todos os atos relativos aos contratos que agenciarem."

19. Lesão Contratual no Direito Brasileiro, Rio de Janeiro: Renovar, 2001, pág. 105.
} 
Diante da conduta dolosa daquele que assina o contrato como agente ou representante do segurador, somado ao fato de que se trata de negócio jurídico estabelecido entre particulares, poder-se-ia pensar na hipótese de ato anulável, pois assim o são aqueles praticados com vício resultante de dolo, segundo dispõe o art. 171 do CCB. ${ }^{20}$

Todavia, nos parece que, diante das circunstâncias específicas, notadamente o interesse público envolvido no correto funcionamento do Sistema Nacional de Seguros Privados, o negócio jurídico estabelecido entre os signatários do contrato seja nulo.

Enzo Roppo ensina que "o contrato é nulo quando a operação juridico-econômica que deveria corresponder-lhe, ou não pode realizar-se ou, podendo embora realizar-se, é reprovada pelo ordenamento jurídico". ${ }^{21}$

Carlos Alberto da Mota Pinto estabelece as distinções entre as figuras da nulidade e da anulabilidade de maneira sucinta e elucidativa, esclarecendo que o negócio nulo, devido à falta ou ao vício de algum dos elementos internos ou formativos, desde o início não produz os efeitos esperados, e que o regime e os efeitos da nulidade são mais severos porque têm fundamento em motivos de interesse público; enquanto que o negócio anulável, igualmente contendo falta ou vício de elemento interno ou formativo, produz efeitos e é tratado como se válido fosse enquanto não for declarado inválido por decisão judicial, a partir da iniciativa de uma das partes, e seus efeitos não são tão severos quanto os da nulidade porque

20. "Art. 171. Além dos casos expressamente declarados na lei, é anulável o negócio jurídico: I - por incapacidade relativa do agente; II - por vício resultante de erro, dolo, coação, estado de perigo, lesão ou fraude contra credores." 21. O Contrato, Tradução de Ana Coimbra e M. Januário C. Gomes, Coimbra: Livraria Almedina, 1988, pág. 195. 
fundam-se na infração de regras relativas à tutela dos interesses privados. ${ }^{22}$

Roppo estabelece, quanto às razões que fundamentam as hipóteses de nulidade e anulabilidade, as mesmas distinções entre o interesse público e o interesse privado referidas por Pinto. ${ }^{23}$

Essas lições, especialmente no que se refere ao envolvimento do interesse público, claramente presente na necessidade de que se respeite a determinação legal de que somente seguradoras autorizadas por lei a atuar como tal contratem seguros, preservando assim o Sistema Nacional de Seguros Privados e garantindo efetividade à tarefa de fiscalização e aplicação de sanções que the incumbe, reforçam nosso entendimento no sentido de que a operação que ora se estuda seja nula, e não anulável.

Não se trata apenas da preservação do interesse dos contratantes diretamente envolvidos, mas do interesse público de que se assegure o correto funcionamento do sistema de seguros, cujo objetivo maior é, como antes mencionado, garantir ao segurado a efetiva reparação dos danos sofridos mesmo em caso de insolvência (ou mero inadimplemento) do agente segurador. Sob esse ponto de vista, não seria razoável que se exigisse, da parte prejudicada, a busca de uma declaração judicial de invalidade do

22 "O negócio nulo não produz, desde o início (ab initio), por força da falta ou vício de um elemento interno ou formativo, os efeitos a que tendia. O negócio anulável, não obstante a falta ou vício de um elemento interno ou formativo, produz os seus efeitos e é tratado como válido, enquanto não for julgada procecente uma acção de anulação; exercido, mediante esta acção, o direito potestativo de anular, pertencente a uma das partes, os efeitos do negócio são retroativamente destruídos. O regime e os efeitos mais severos da nulidade encontram o seu fundamento teleológico em motivos de interesse público predominante. As anulabilidades fundam-se na infraç̧ão de requisitos dirigidos à tutela de interesses predominantemente particulares." (Teoria Geral do Direito Civil, Coimbra: Coimbra Editora, 1999, pág. 610)

23. "Enquanto a anulabilidade, como veremos, está geralmente disposta à tutela dos interesses particulares de uma das partes do contrato, em regra a lei comina a nulidade todas as vezes em que dar actuação ao negócio contraria exigências de carácter geral, ou o interesse público." (Ob. cit., pág. 205).V - Quando a lei taxativamente o declarar nulo ou lhe negar efeito. 
negócio, tendo-se como válidos os negócios em que tal declaração não fosse obtida.

Assim, vislumbramos a nulidade do contrato, por força do disposto no art. 166, inc. II, do CCB atualmente vigente ${ }^{24}$

Entendemos que o objeto do contrato é ilícito porque, de acordo com os anteriormente citados artigos 757, par. único, do Código Civil, e 24, do DL 73/66, somente entidades devidamente autorizadas podem atuar como seguradoras, donde conclui-se que, em sendo o contrato firmado por quem não tem autorização legal para operar em seguros privados (e sequer segurador é), possui objeto contrário à lei (seguro tendo como segurador quem não possui autorização para atuar como tal) e, portanto, ilícito.

A lição de Carvalho Santos a respeito do que vem a ser o objeto ilicito parece acolher a tese que aqui se defende, pois o comentarista afirma que a ilicitude "tem por fundamento disposição de lei que, embora infringida, não torna impossivel a formação do ato, mas apenas se limita a não consentir que ele produza efeitos, tal como se verifica na dívida proveniente de jogo."25

Quanto ao segurado, é inegável que age de boa-fé, iludido por uma proposta aparentemente legal, pois nenhuma pessoa, em que pese o valor inferior ao preço dos demais seguros existentes no mercado, contrata seguro sabidamente nulo, que não irá gerar a indenização prometida em caso de sinistro.

E o princípio da boa-fé, no caso, boa-fé objetiva (o que pode se entender, segundo Judith Martins-Costa, como sendo "modelo de conduta social, arquétipo ou standard jurídico", segundo o qual "cada pessoa deve ajustar a própria conduta a este arquétipo, obrando como obraria um homem reto: com honestidade, lealdade, probidade"26; ou, segundo Jorge Mosset Iturraspe, como

24 "Art. 166. É nulo o negócio jurídico quando : ... II - Quando for llícito, ou impossivel seu objeto; ... , segundo o qual é nulo o negócio jurídico quando foi ilícito seu objeto.

"25. Código Civil Brasileiro Interpretado, $11^{\mathrm{a}}$ ed. Rio de Janeiro: Freitas Bastos, 1980, vol. III, pág. 237.

26. A Boa-Fé no Direito Privado, São Paulo: Revista dos Tribunais, 1999, pág. 411. 
sendo a espécie que "expresa la lealtad, honestidad, probidad y confianza en el comportamiento"27; ou ainda, no que se refere aos contratos, como sendo a pauta de conduta negocial a ser obedecida pelos contratantes), está consagrado nas cláusulas gerais de boafé contidas nos artigos $4^{\circ}$, inc. III, do Código de Defesa do Consumidor ${ }^{28}$ e 422 do $\mathrm{CCB}^{29}$ e, especificamente em relação ao seguro, no art. 765 do CCB de 2002. ${ }^{30}$

Assim, com base nos ditames do Código Civil e do Código do Consumidor, poder-se-ia invocar o princípio da boa-fé objetiva, que pautou a conduta do segurado, mas não foi obedecido pelo pretenso agente ou representante do segurador, a fim de preservar certos efeitos do negócio jurídico através da aplicação, ao caso vertente, do instituto da redução, previsto no art. 170 do $\mathrm{CCB}^{31}$, o que viria em benefício do interesse particular do segurado.

Todavia, em primeiro lugar, diante dos próprios termos do art. 170, entendemos que não seria caso de redução, uma vez que a lei refere o fim que as partes teriam querido, caso houvessem previsto a nulidade, o que implicaria na hipótese de que ambos contratantes estivessem agindo de boa-fé, hipótese que não se verifica no caso em comento.

27. Interpretacion Economica de los Contratos, Santa Fé: Rubinzal-Culzoni Editores, 1994, pág. 211.

28. "Art. 40. A Política Nacional das Relações de Consumo tem por objetivo o atendimento das necessidades dos consumidores, o respeito à sua dignidade, saúde e segurança, a proteção de seus interesses econômicos, a melhoria da sua qualidade de vida, bem como a transparência e harmonia das relações de consumo, atendidos os seguintes princípios: ... III - harmonização dos interesses dos participantes das relações de consumo e compatibilização da proteção do consumidor com a necessidade de desenvolvimento econômico e tecnológico, de modo a viabilizar os princípios nos quais se funda a ordem econômica (artigo 170 , da Constituição Federal), sempre com base na boa-fé e equilíbrio nas relações entre consumidores e fornecedores;"

29. "Art. 422. Os contratantes são obrigados a guardar, assim na conclusão do contrato, como em sua execução, os princípios de probidade e boa-fé."

30. "Art. 765. O segurado e o segurador são obrigados a guardar, na conclusão e na execução do contrato, a mais estrita boa-fé e veracidade, tanto a respeito do objeto como das circunstâncias e deciarações a ele concernentes."

31. "Art. 170 . Se, porém, o negócio jurídico nulo contiver os requisitos de outro, subsistirá este quando o fim a que visavam as partes permite supor que o teriam querido, se houvessem previsto a nulidade. 
Além disso, seria difícil compatibilizar o interesse privado do contratante com o interesse público na preservação do Sistema Nacional de Seguros Privados (especialmente de suas funções de fiscalização e garantia de reparação dos danos sofridos pelos segurados), pois a possibilidade de convalidação de alguns negócios praticados por entes não autorizados a atuar como seguradores no mercado nacional traria incerteza ao mercado e poderia gerar, inclusive, um incentivo à proliferação dessa espécie de negócio.

Ainda que se entendesse possivel contornar os óbices acima levantados, pensamos que somente haveria a possibilidade de saneamento do contrato caso houvesse efetiva participação do pretenso segurador estrangeiro na contratação, ou seja, fosse ele efetivamente representado pelo agente que firmou o contrato. Em tal hipótese, encontraríamos na jurisprudência a aplicação, a casos semelhantes, da teoria da aparência de direito, podendo se responsabilizar contratualmente tanto o segurador quanto o suposto agente.

Exemplificando, tem-se o posicionamento adotado pela $3^{\text {a }}$ Turma do STJ no julgamento do Recurso Especial $n^{\circ} 56.199 /$ $\mathrm{GO}^{32}$, decisão a qual, embora não tenha envolvido empresa

"32. "PROCESSUAL E COMERCIAL - CONTRATO DE SEGURO - ILEGITIMIDADE AD CAUSAM DESCARACTERIZADA - MATERIA DE PROVA I. A ilegitimidade ad causam não se caracteriza quando dos elementos concretos do contrato de seguro, dos fatos e provas emergiu o titular que deve assumir o pólo passivo da ação. II. Matéria de fato não se reexamina em Especial (Súmula 07/STJ). III. Recurso não-conhecido." (Recurso Especial n 56.199/CO - (Reg. 94/00327404) - Relator: Ministro WALDEMAR ZVEITER; ReconvInte: Banco do Brasil S/A; Recorrido: Dalva Sabina Pasquotto Saltes e Outros; Advogados: Drs. Paulo Cesar Calleri e Outros e Gesner Jose Le Senechal Horta e Outro) De ver-se, pois, pelo contexto do aresto, que a solução jurídica da lide teve como base fática os elementos concretos apresentados no processo, emergindo do contrato e dos fatos a legitimidade do Banco para figurar no pólo passivo do pedido proveniente do contrato de seguro avençado com os recorridos. Assim, os documentos e instrumentos do negócio jurídico de que se cuida não afastam a obrigatoriedade do recorrente, nem este logrou comprovar sua posição de simples intermediador ou corretor. Enfim, o aresto apresenta-se escorreito na orientação que adotou para o desfecho da demanda:" (in Marensi, Voltaire Giavarina O Seguro no Direito Brasileiro: excertos doutrinários, jurisprudência comentada, legisiação, $3^{a}$ ed. Porto Alegre: Síntese, 1996. págs. 256/259) 
estrangeira, responsabiliza o Banco do Brasil, que não tem autorização para atuar como Sociedade Seguradora, a indenizar segurado, em razão de constar o nome da instituição financeira como expedidora do certificado de seguro e recebedora das prestações. Em tal hipótese, porém, como se verifica da leitura atenta do acórdão, havia seguro regularmente contratado com Sociedades Seguradoras autorizadas legalmente a comercializar seguros privados no país.

Do voto do Min. Relator, Dr. Waldemar Zveiter, bem se percebe que a situação tratada no acórdão é distinta da que se aborda no presente artigo, uma vez que a operação de seguro era legal, havendo intervenção de Sociedades Seguradoras autorizadas, tendo apenas faltado a ciência clara de tal dado no contrato, pelo que o mesmo foi reputado válido e o Banco do Brasil parte legítima para responder pelas obrigações contratadas. ${ }^{33}$

Nos autos de embargos, o Banco do Brasil S/A argúi, em preliminar, ilegitimidade ad causam. Justifica sua atuação no agenciamento de clientes para formação de seguros em grupo, enfatizando que sua corretora 'BB Corretora de Seguros e Administradora de Bens' firmou o contato como inter-mediária de uma das seguintes Companhias de Seguros: Sul América Seguros, Minas Brasil Internacional de Seguros e Seguradora Brasileira Iraquiana. Pois bem. Às fls. 15 e 14 da Ação de Execução (processo em apenso), estão inseridas as duas apólices em que figura como segurado Jorge Assad Salles e emitente o Banco do Brasil S/A. Também, às fls. 15 e 16, vê-se duas correspondências encaminhadas ao segurado, demonstrando a posição de seu seguro, pela BB Corretora de Seguros, como se ele próprio fosse o segurador. Dessarte, há de se convir que o contrato de seguro

33 "Nos Embargos à Execução decretou-se a carência da ação (art. 267, VI, do CPC) para demandar o Banco do Brasil S/A a pagar indenização contratante de apólice de seguro às demandadas, ora recorridas. Todavia, a llegitimidade do estabelecimento bancário foi afastada pelo aresto recorrido, nestes termos (fls. 81/82): 
foi feito inquestionavelmente pelo Banco do Brasil S/A ou BB Corretora de Seguros.

Não há nos autos nenhum documento ou cópia de correspondência do Banco do Brasil endereçada ao segurado Jorge Assad Salles, comunicando-Ihe o nome da Companhia de Seguros a que foi repassado o seguro em grupo, para cumprimento da obrigação avençada. É, pois, responsável no pólo passivo da execução da apólice de seguro o Banco do Brasil S/A, que expediu certificado individual (Apólice $n^{\circ}$ 5.901) de Seguro de Vida em Grupo (doc. fls. 13 e 14) e recebeu do segundo normalmente as contraprestações. Prevalece, portanto, o conceito jurídico de que a cada direito corresponde uma obrigação. Irrelevante o argumento de que o Banco do Brasil S/A não tem a carteira de seguradora. O que importa é que agindo como tal contraiu a obrigação contratual, o que dá ao credor o direito à ação.

Houvesse mais clareza e responsabilidade contratual pelo Banco do Brasil, ao vender o prêmio-seguro a Jorge Assad Salles, indicando o nome e a documentação da Companhia a que tenha repassado a obrigação, os beneficiários teriam proposto a ação contra quem de direito.

Poderia, ainda, o Banco do Brasil S/A, ao opor os Embargos, oferecer tais documentos; entretanto, perdeu-se com evasivas. Ademais, poderia, ainda se quisesse, dar maior transparência em seus compromissos assumidos, promover a denunciação da lide à Cia. Seguradora que, na função de corretora de seguros, segundo afirma, tenha repassado a obrigação secundária.

A jurisprudência, em casos que tais, admite a denunciação à lide, in verbis:'É procedente a denunciação da lide à Cia. Seguradora em se tratando do seguro facultativo de responsabilidade civil por força de ser a mesma obrigada 
regressivamente' (TJSP Ac. unânime da 6 Câmara de 12.09.74, in O Proc. Civil à Luz da Jurisprudência. rol. 01, pág. 475, de ALEXANDRE DE PAULA.)."

Na hipótese que ora se estuda, porém, o pseudo-agente, que afirma ser representante contratual do segurador posto no contrato como garantidor do risco, não o é. Não há aqui contrato de seguro, pelo que não se pode imputar ao segurador referido no contrato responsabilidade por situação que desconhece e, dessa forma, sequer poderia coibir.

Portanto, voltando ao caso sob análise, quem pode ser responsabilizado é o signatário do contrato nulo. E esse, ao fazer falsa afirmativa de que representava a seguradora posta no contrato como garantidora do risco, bem como, ao afirmar que essa tinha autorização para operar no mercado de seguros brasileiro, o que não se verifica, praticou ato ilícito, não apenas do ponto de vista da lei civil como também da lei penal (o que não se pretende abordar no presente artigo, onde se busca tratar da responsabilização civil do signatário do contrato, em busca da indenização do segurado).

Sendo assim, responsabilidade contratual, decorrente de avença securitária, não haveria, mas sim responsabilidade extracontratual, decorrente do ato ilicito praticado, encontrando fundamento para providência na busca de ressarcimento nos arts. 186 e 927 do Código Civil Brasileiro. ${ }^{34}$

Examinada a situação em tela à luz da lição de Pontes de Miranda, citada por J. M. de Carvalho Santos, segundo a qual, para que o ato gere responsabilidade extracontratual, deve serimputável ao réu, danoso e ilicito, fica patente a existência de responsabilidade extracontratual do firmatário do contrato, que alega agir em nome do segurador. ${ }^{35}$

34 "Art. 186. Aquele que, por ação ou omissão voluntária, negligência, ou imprudência, violar direito e causar dano a outrem, ainda que exclusivamente moral, comete ato ilícito. ${ }^{\prime \prime}$ Art. 927. Aquele que, por ato ilícito (arts. 186 e 187), causar dano a outrem, fica obrigado a repará-lo.

"35. "São elementos para que o ato gere a responsabilidade extracontratual: a) um ato ou omissão; b) imputável ao réu, salvo casos excepcionais de reparação sem imputabilidade; c) danoso, por perda ou privação de ganho; d) ilícito." (Código Civil Brasileiro Interpretado, $11^{\mathrm{a}} \mathrm{ed}$. Rio de Janeiro: Freitas Bastos, 1980, vol. III, pág. 318) 
Existe um ato ou omissão daquele que firma o contrato na posição de representante do segurador, qual seja, a apresentação de proposta e assinatura de contrato nulo como se legal fosse; tal atitude, por óbvio, é imputável a quem assina o contrato de próprio punho; o ato é danoso, pois priva o segurado do recebimento da indenização em caso de sinistro; o ato é ilícito, pois o contrato é assinado, na condição de segurador, por pessoa à qual a lei brasileira não reconhece tal condição.

Sustentamos ainda que, além do falso agente ou representante do segurador, o corretor de seguros que intermediou o negócio pode ser responsabilizado. Nos termos do disposto no art. 122 , do DL. $73 / 66$, é ele o intermediário autorizado a angariar e promover os contratos entre seguradores e segurados. ${ }^{36}$ Ainda, segundo o art. 126, do DL 73/66, o corretor de seguros responde civilmente perante os segurados por culpa ou dolo. ${ }^{37}$

E no ato praticado pelo corretor negligente ou doloso, ao promover a assinatura do contrato nulo, cujo risco é teoricamente repassado a empresa sem autorização para atuar como seguradora no Brasil (e se o risco é repassado ao exterior, necessária seria a intervenção do IRB), encontramos os mesmos elementos geradores da responsabilidade extracontratual antes mencionados, motivo pelo qual parece clara a possibilidade de o segurado prejudicado buscar ressarcimento tanto junto ao falso agente do segurador quanto em relação ao corretor de seguros que intermediou o negócio, em caso de não recebimento da indenização contratada para os casos de sinistro.

\footnotetext{
36. "Art. 122. O corretor de seguros pessoa física ou jurídica, é o intermediário legalmente autorizado a angariar e promover contratos de seguro entre as Sociedades Seguradoras e as pessoas físicas ou jurídicas de Direito Privado. "37. "Art. 126. O corretor de seguros responderá civilmente perante os segurados e as Sociedades Seguradoras pelos prejuízos que causar, por omissão, imperícia ou negligência no exercício da profissão.
} 


\section{VIII - DA POSSIBILIDADE DE ENQUADRAMENTO DAS}

CONDUTAS DO SUPOSTO AGENTE OU REPRESENTANTE DO SEGURADOR E DO CORRETOR DE SEGUROS NAS HIPÓTESES PREVISTAS NO CÓDIGO DE DEFESA DO CONSUMIDOR

Diante do disposto nos arts. $2^{\circ}$, caput, e $3^{\circ}$, caput e $\S 2^{\circ}$, do CDC (Lei n $\left.{ }^{0} 8.078 / 90\right)^{38}$, o primeiro definindo consumidor e o segundo definindo fornecedor e apontando o seguro entre os serviços por ele prestados, se poderia pensar que todas as operações de seguro caracterizam relações de consumo e, como tal, estão submetidas aos ditames do micro-sistema de defesa dos direitos do consumidor, como sugerem os adeptos da teoria maximalista, para os quais o CDC seria o diploma legal aplicável a todo o mercado de consumo nacional, protegendo tanto os consumidores não-profissionais como os profissionais.

Todavia, não é esta a opinião dominante na doutrina nacional. Segundo os adeptos da teoria finalista, que se opõe à maximalista, entre os quais se destacam Antonio Herman $V$. Benjamin, Eros Roberto Grau e Cláudia Lima Marques ${ }^{39}$, com os quais concordamos, somente serão relações de consumo os

"38. "Art. $2^{\circ}$. Consumidor é toda a pessoa física ou jurídica que adquire ou utiliza produto ou serviço como destinatário final."

"Art. $3^{\circ}$. Fornecedor é toda pessoa física ou jurídica, pública ou privada nacional ou estrangeira, bem como os entes despersonalizados, que desenvolvem atividades de produção, montagem, criação, construção, transformação, importação, exportação, distribuição ou comercialização de produtos ou prestação de serviços. ... $\S 2^{\circ}$. Serviço é qualquer atividade fornecida no mercado de consumo, mediante remuneração, inclusive as de natureza bancária, financeira, de crédito e securitária, salvo as decorrentes das relações de caráter trabalhista. "39. "O destinatário final é o Endverbraucher, o consumidor final, o que retira o bem do mercado ao adquirir ou simplemente utilizá-lo (destinatário final fático), aquele que coloca um fim na cadeia de produção (destinatário final econômico) e não aquele que utiliza o bem para continuar a produzir $r_{r}$ pois ele não é o consumidor final, ele está transformando o bem, utilizando o bem para oferecêlo por sua vez ao seu cliente, seu consumidor". (Contratos no Código de Defesa do Consumidor: o novo regime das relações contratuais, $3^{a}$ ed. São Paulo: Revista dos Tribunais, 1992, pág. 150). 
contratos de seguro onde o destinatário final do serviço (o segurado) seja efetivamente seu destinatário fático e econômico.

Naqueles contratos onde o destinatário do serviço dele se utilizar como insumo, não haverá relação de consumo. Exemplificando, uma empresa de transporte de valores não é consumidora em um contrato de seguro firmado para garantir o patrimônio de terceiros por ela transportado em sua atividade diária.

Nossos tribunais, embora não de forma unânime, vêm seguindo a teoria finalista, interpretando restritivamente 0 art. $2^{\circ}$ do CDC. ${ }^{40}$

Feita a necessária ressalva e analisadas, a partir daí, especificamente as relações negociais estabelecidas tendo como contratante um consumidor, igualmente poder-se-ia responsabilizar o suposto agente ou representante do segurador que firma o contrato (e até o próprio corretor de seguros através do qual a

40. "SEGURO - AÇÃOO DE COBRANÇA CUMULADA COM PERDAS E DANOS

- JULGAMENTO ANTECIPADO DA LIDE

- IMPROCEDÊNCIA DO PEDIDO

- RECURSO DA SEGURADA

- CONTRATO DE ADESÃO

- INAPLICABILIDADE DAS NORMAS DO CDC

- INTERPRETAÇÃO DAS CLÁUSULAS DO CONTRATO

- DISTINÇÃO ENTRE FURTO E ROUBO

- INDENIZACÃAO DEVIDA

- PROCEDÊNCIA PARCIAL DA DEMANDA

- PROVIMENTO DO RECURSO

- 1. Inaplicável ao contrato de seguro as disposições do Código de Defesa do Consumidor (Lei no 8.078/90), quando a segurada, na qualidade de fornecedora de serviços de contabilidade, não se caracteriza como consumidora (destinatária final dos serviços), nos termos do art. $2^{\circ}$ da lei de regência. 2. Como típico contrato de adesão, as cláusulas do contrato de seguro devem ser interpretadas em favor do segurado. 3. Para o segurado, como leigo, o furto e o roubo são expressões que se equivalem, e ocorrido o furto qualificado, com a subtração de bens do estabelecimento prestador de serviços, é devida a indenização pela seguradora, inclusive pelo princípio da boa-fé, inafastável das relações jurídicas securitárias. 4. Recurso provido para julgar parcialmente procedente a demanda." (TAPR - AC 0121458-8 - (11131) - 5a C.Cív. - Rela Juíza Denise Arruda - DJPR 15.09.2000, in Júris Síntese Millenium, Porto Alegre: Síntese, jan/fev/2004) II aceitar outro produto ou prestação de serviço equivalente; III - rescindir o contrato, com direito à restituição de quantia eventualmente antecipada, monetariamente atualizada, e a perdas e danos." 
contratação é efetuada) por recusa de cumprimento de oferta, hipótese prevista no art. 35 do CDC (Lei n ${ }^{\circ} 8.078 / 90$ ), na medida em que a oferta anunciada acabará por não ser cumprida. ${ }^{41}$.

"Art. 35. Se o fornecedor de produtos ou serviços recusar cumprimento à oferta, apresentação ou publicidade, o consumidor poderá, alternativamente e à sua livre escolha: 1 - exigir o cumprimento forçado da obrigação, nos termos da oferta, apresentação ou publicidade;

Todavia, somos da opinião que, neste caso, caberia ao consumidor que teve recusado o cumprimento da oferta, escolher tão somente entre as opções previstas nos incisos II (aceitar outro produto ou prestação de serviço equivalente) e III (rescindir o contrato, com direito à restituição de quantia eventualmente antecipada, monetariamente atualizada, e a perdas e danos) do referido artigo 35, uma vez que, não tendo aquele que se apresenta como agente ou representante do segurador autorização para contratar seguros no Brasil, não poderá ser forçado a cumprir a obrigação nos termos da oferta, que era de contrato de seguro.

\section{IX - CONCLUSÃO}

A partir das observações acima lançadas, entendemos que o contrato de seguro firmado por suposto agente ou representante contratual de segurador que não está autorizado a atuar no mercado de seguros nacional é nulo e, como tal, não pode ensejar discussões a respeito de eventual responsabilidade contratual de indenizar o segurado em caso de ocorrência de sinistro.

Diante de tal cenário, sustentamos que o caminho natural do contratante que, de boa-fé, assina tal espécie de contrato, na busca da defesa de seus interesses, é o ajuizamento de ação ordinária de indenização por ato ilícito contra a pessoa, física ou jurídica, que firma o contrato na condição de segurador ou representante contratual desse. 
Da mesma forma, o corretor de seguros que participa do negócio deve ser responsabilizado, pois é de sua atuação, na condição de intermediário entre segurador e segurado, que, segundo a lei, parte a oferta do seguro e, havendo negligência no exame do negócio, cabe sua inclusão no pólo passivo de eventual ação ordinária de indenização por ato ilicito.

É evidente que se recomenda àquele que pretende recorrer à via judicial para tentar obter indenização pelos prejuízos sofridos que, por medida de economia, antes de ingressar em juízo, promova ampla investigação referente à eventual existência de patrimônio de propriedade dos responsáveis, capaz de garantir a indenização pleiteada, ou pelo menos parte dela. Tal medida mostra-se salutar, pois evitaria o ajuizamento de ação que, embora venha a ser julgada procedente, não resulte, na prática, na reparação dos prejuízos.

Por outro lado, para colaborar com o aperfeiçoamento do Sistema Nacional de Seguros Privados e para tornar mais eficiente a fiscalização de seu correto funcionamento, o que pode evitar a ocorrência de novas fraudes semelhantes, deve ainda o prejudicado denunciar o falso representante contratual do segurador e o corretor que intermediou o contrato à SUSEP, para que o órgão estatal tome as medidas punitivas aplicáveis à espécie, sem prejuízo da eventual comunicação à autoridade policial e ao Ministério Público, para que investiguem a prática de ilícito penal. 


\section{BIBLIOGRAFIA}

ALVIM, Pedro, O Contrato de Seguro, $3^{\mathrm{a}}$ ed. Rio de Janeiro: Forense, 1999.

BEVILAQUA, Clóvis, Direito das Obrigações, Campinas: Red Livros, 2000.

BULGARELLI, Waldírio, Contratos Mercantis, $10^{\text {a }}$ ed. São Paulo: Atlas, 1998.

CARVALHO SANTOS, J. M. de, Código Civil Brasileiro Interpretado, $11^{\mathrm{a}}$ ed. Rio de Janeiro: Freitas Bastos, 1980.

GHERSI, Carlos Alberto, Contratos civiles y comerciales, $4^{\text {a }}$ ed. Buenos Aires: Astrea, 1999.

ITURRASPE, Jorge Mosset, Interpretacion Economica de los Contratos, Santa Fé: Rubinzal-Culzoni Editores, 1994.

MARTINS, Marcelo Guerra, Lesão Contratual no Direito Brasileiro, Rio de Janeiro: Renovar, 2001.

MARENSI, Voltaire Giavarina, O Seguro no Direito Brasileiro: excertos doutrinários, jurisprudência comentada,legislação, $3^{a}$ ed. Porto Alegre: Síntese, 1996.

MARQUES, Cláudia Lima, Contratos no Código de Defesa do Consumidor: o novo regime das relações contratuais. São Paulo: Revista dos Tribunais, 1992.

MARTINS-COSTA, Judith, A Boa-Fé no Direito Privado, São Paulo: Revista dos Tribunais, 1999.

NEGRÃO, Theotonio, e GOUVÊA, José Roberto Ferreira, Código Civil: e legislação civil em vigor, $23^{\mathrm{a}}$ ed. São Paulo: Saraiva, 2004.

NERY JR., Nelson e ANDRADE NERY, Rosa Maria de, Novo Código Civil, e Legislação Extravagante Anotados, São Paulo: Revista dos Tribunais, 2002.

PINTO, Carlos Alberto da Mota, Teoria Geral do Direito Civil, $3^{a}$ ed. Coimbra: Coimbra Editora, 1999.

PONTES DE MIRANDA, Francisco Cavalcanti, Tratado de Direito Privado: direito das obrigações, $2^{\mathrm{a}}$ ed. Rio de Janeiro: Borsoi, 1964. 
ROPPO, Enzo, O Contrato (Tradução de Ana Coimbra e M. Januário C. Gomes), Coimbra: Livraria Almedina, 1988.

VENOSA, Sílvio de Salvo, Direito Civil, $4^{\mathrm{a}}$ ed. São Paulo: Atlas, 2004. 